\title{
Habitual yoghurt consumption and depressive symptoms in a general population
}

study of 19,596 adults

Bin Yu 1,3,4, Qi Zhu 1, Ge Meng 1, Yeqing Gu 1, Qing Zhang 2, Li Liu 2, Hongmei Wu 1, Yang Xia 1, Xue Bao 1, Hongbin Shi 2, Qian Su 1, Liyun Fang 1, Fei Yu 1, Huijun Yang 1, Shaomei Sun 2, Xing Wang 2, Ming Zhou 2, Qiyu Jia 2, Qi Guo 5, Kun Song 2, Andrew Steptoe 3, and Kaijun Niu 1, 2†.

1 Nutritional Epidemiology Institute and School of Public Health, Tianjin Medical University, Tianjin, China.

2 Health Management Centre, Tianjin Medical University General Hospital, Tianjin, China.

3 Department of Epidemiology and Public Health, University College London, London, United Kingdom.

4 Institute of Psychology, Tianjin Medical University, Tianjin, China.

5 Department of Rehabilitation and Sports Medicine, Tianjin Medical University, Tianjin, China.

$\dagger$ Address for correspondence to: Kaijun Niu, MD, $\mathrm{PhD}$

Nutritional Epidemiology Institute and School of Public Health, Tianjin Medical University, 22 Qixiangtai Road, Heping District, Tianjin 300070, China. Tel: +86-22-83336613

E-mail address: nkj0809@gmail.com or niukaijun@tmu.edu.cn

Declaration of interest: None. 
1 Purpose Epidemiological studies directly examining the association between habitual

2 yoghurt consumption and mental health remain scarce. The aim of this study is to investigate

3 the association of yoghurt consumption with depressive symptoms in adults.

4 Methods This is a cross-sectional study of 19,596 Chinese adults (mean age: 41.2, standard

5 deviation: 11.8 years; males, 54.3\%). Depressive symptoms were assessed using the Self-

6 Rating Depression Scale (SDS). Dietary intake was obtained through a valid food frequency

7 questionnaire. Multiple logistic regression analysis was conducted to assess the association

8 between yoghurt consumption and depressive symptoms. A number of potential confounders

9 were adjusted in the model.

10 Results The prevalence of elevated depressive symptoms was $17.1 \%$ (SDS $\geq 45$ ). The 11 multivariable adjusted odds ratios $(95 \% \mathrm{CI})$ of having elevated depressive symptoms by 12 increasing levels of yoghurt consumption (1-3 times/week, 4-7 times/week, and $\geq$ twice/day) were $1.05(0.96,1.15), 1.02(0.91,1.15)$ and $2.10(1.61,2.73)$ in comparison with lowest consumption group (<once/week or hardly ever).

15 Conclusions These findings suggest no significant association between habitual yoghurt consumption and self-reported depressive symptoms, while the relatively high frequency of yoghurt consumption ( $\geq$ twice/day), which was seen in a small subset of subjects, was associated with increased depressive symptoms. These results need to be interpreted with caution because of the cross-sectional nature of the data.

Keywords: yoghurt consumption, probiotics, depressive symptoms, cross-sectional study

\section{Introduction}

Depression is a major public health problem that is linked to disability, premature death and economic burden [1]. There is growing evidence that modifiable lifestyle factors, 
including dietary composition, may play an important role in the development of depression [2,3]. Epidemiological studies have shown that certain nutrients such as folate [4], as well as zinc [5] and omega-3 fatty acids [6] are related to a lower risk of depression. The beneficial effects of certain foods (e.g. tomato or nuts) on depressive symptoms have also been reported in recent years $[7,8]$. It is also thought that the gut microbiome contributes to mental health [9], so foods influencing gut microbiota may be relevant.

Yoghurt, which is defined by The Codex Standard as the product of milk fermentation by Lactobacillus delbrueckii subspecies bulgaricus and Streptococcus thermophilus [10], is recognized as a nutrient-dense food associated with healthy eating. The consumption of yoghurt may induce changes to the balance and metabolic activities of the indigenous microbiota $[11,12]$. As a probiotic-carrier food, the possible beneficial effects of yoghurt on mental health are interesting in view of the growing body of evidence supporting a role of probiotics in regulating the brain and subsequent emotional behavior. Preclinical evaluation in rodents suggests that manipulation of the gut microbiota with specific probiotics can influence depression-like behaviors [13,14]. Potential mechanisms for these effects include decreasing intestinal permeability, reducing gut inflammation, reducing stress responses via the hypothalamic-pituitary-adrenal (HPA) axis, restoring BDNF levels, and altering GABA receptor expression $[15,16]$. Several human trials have also found that consumption of probiotics or probiotic-containing milk can improve the mood in volunteers [17-19]. A brain imaging study in humans has shown that four weeks of consuming the fermented milk product containing a combination of probiotics reduced brain activity in a network of brain areas involved in processing negative emotional facial expressions [20]. Another recent study found that 24-week intake of probiotic supplementation combined with 
a weight-reducing program led to a significant decrease in the depression score in female compared with the placebo-controlled group[21].

Despite these pieces of preclinical and clinical evidence, epidemiological evidence for an association between yoghurt consumption and mental health is sparse. Only one prospective cohort study with Spanish adults found that habitual yoghurt consumption was not associated with improved health-related quality of life using a measure that included mental health [22]. To our knowledge, there are no epidemiological studies specifically examining the association of yoghurt consumption with mental health. The objective of this study was therefore to examine the association between habitual yoghurt consumption and depressive symptoms in the general population. Based on previous evidence, we hypothesised a dose-response effect, so that adults who have a higher level of yoghurt consumption would experience lower levels of depressive symptoms. 


\section{Methods}

\section{Study participants}

This cross-sectional study used data from the Tianjin Chronic Low-grade Systemic Inflammation and Health (TCLSIH) Cohort. TCLSIH is a large prospective cohort study focusing on the relationships between chronic low-grade systemic inflammation and the health status of a population living in Tianjin, China. Information on the research design and data collection of the TCLSHI has been detailed elsewhere[23]. Study protocols and procedures were approved by the Institutional Review Board of Tianjin Medical University. Written informed consent was obtained from all participants.

During the study period, a total of 22,265 participants aged 20 years and older were sampled. We excluded participants who did not complete data collection on food frequency questionnaire or depression scale $(\mathrm{n}=903)$, or those with a history of cardiovascular disease $(n=1,323)$ or cancer $(n=443)$. Thus, 19,596 participants (mean age 41.2, SD: 11.8 years; males, $54.3 \%$ ) were included in this analysis.

\section{Measures}

\section{Assessment of depressive symptoms}

Depressive symptoms were measured using the Chinese version of Self-Rating Depression Scale (SDS), which has been confirmed as a reliable and valid measure in the Chinese population [24]. There are 20 items rated on a 4-point scale, with half being formulated in positive terms and half in negative terms. Summary scores could range from 20 to 80 , with higher values indicating greater depressive symptoms. In order to increase sensitivity, two cutoffs (45 and 50) were used to define depressive symptoms in the present study $[25,26]$. Scores higher than these cutoffs are considered to reflect a positive screening 
result. In this study Cronbach's alpha was 0.82 .

Assessment of dietary intake

Dietary intake was obtained through a food frequency questionnaire (FFQ) that includes 100 food items with specified serving sizes. The FFQ includes 7 frequency categories ranging from 'hardly ever' to 'twice or more per day' for foods (including yoghurt and milk) and 8 frequency categories ranging from 'hardly ever' to 'four or more times per day' for beverages. The average daily nutrients intake was calculated with a computer program based on Chinese Food Composition Table [27]. The reproducibility and validity of the FFQ were evaluated in a random sample of 150 participants from our cohort by using data from repeated measure approximately 3 months apart and 4-day weighed diet records (WDRs). For example, the correlation coefficient for energy intake between two FFQs was $0.68(\mathrm{p}<0.0001)$. Correlation coefficients for food items (fruits, vegetables, fish, meat, and beverages) between two FFQs ranged from 0.62 to $0.79(\mathrm{p}<0.0001)$. Spearman's rank correlation coefficient for energy intake between the WDRs and the FFQ was 0.49 ( $p<$ 0.001). By combining the information obtained from the food frequency response with the food composition table, we were also able to compute the mean total energy intake for each participant.

\section{Assessment of other variables}

All participants received standardized physical examinations at the Health Management Center. Waist circumference was measured in standing position at the level of the umbilicus. Blood pressure (BP) was measured twice on the upper left arm in a sitting position and the average used for analysis. Fasting blood sugar (FBS) was measured using 
the glucose oxidase method. Triglycerides (TG) were measured using the enzymatic colorimetric method. Low-density lipoprotein cholesterol (LDL) and high-density lipoprotein cholesterol (HDL) were measured with an autoanalyzer (Roche Cobas 8000 modular analyzer, Mannheim, Germany). Body mass index (BMI) was calculated as weight (kilograms) divided by height (meters) in squared. Metabolic syndrome (MetS) was defined according to the criteria of the American Heart Association Scientific Statement [28].

Sociodemographic variables including sex, age, education, occupation, household income and social connections (including marital status, cohabitants, and amount of social contact) were also assessed. For education, we classified respondents according to whether or not they were college graduates, while income was classified into two groups using the threshold of 10,000 yuan per month. Occupation was classified according to the Chinese Standard Classification of Occupations (CSCO) [29] into three groups: Managers, Professionals, and others. The frequency of social contact was measured by the question, "do you often visit your friends?" Previous and current smoking and drinking status were assessed by questionnaire. Physical activity (PA) in the most recent week was assessed using the short form of the International Physical Activity Questionnaire (IPAQ) [30]. For evaluation of total PA, separate metabolic equivalent (MET) hours per week were calculated for walking, moderate, and vigorous activities according to the following formulas: MET coefficient of activity * duration (hour) * frequency (day). The corresponding MET coefficients for these PA categories were 3.3, 4.0 and 8.0 respectively (one MET is defined as metabolic expenditure at rest) [30]. Total PA levels were assessed by combining separate scores for different activities.

\section{Statistical analysis}



percentages. Four categories of yoghurt consumption were used to classify the participants: $<$ once/week or hardly ever, 1-3 times/week, 4-7 times/week and $\geq$ twice/day. Differences in covariates between the yoghurt consumption categories were examined by analysis of variance for continuous variables or by logistic regression analysis for categorical variables. Depressive symptoms were analyzed as binary variables using the lower $(\geq 45)$ and higher $(\geq 50)$ cutoff points. Logistic regression models were fitted to assess the associations between yoghurt consumption categories and depressive symptoms, using the lowest category of yoghurt consumption (<once/week or hardly ever) as the reference group. For all analyses, we fitted a crude univariate model (model 1), an age-, sex- and BMI-adjusted model (model 2), and a multivariable model (model 3) after additional adjustment for the following potential confounders: previous and current smoking and drinking status, PA, educational level, employment status, household income, cohabitants, amount of social contact, marital status, total energy intake, MetS and frequency of milk consumption. The final multivariate logistic analysis was performed with the forced entry of all factors considered to be potential covariates. The interactions between yoghurt consumption and sex for depressive symptoms were tested through the addition of the cross-product term to the final regression model. All $\mathrm{p}$ values for linear trends were calculated by using the categories of yoghurt consumption. All $\mathrm{p}$ values presented are two-tailed and $p<0.05$ was considered statistically significant. All the statistical analyses were performed by using SAS version 9.1 . 


\section{Results}

The mean SDS score was 36.8 , with a median of $37.0 ; 17.1 \%$ were classified as having moderate to severe depressive symptoms when using 45 as cutoff, and $6.6 \%$ with the higher cutoff of 50. The main characteristics of participants according to categories of yoghurt consumption are presented in Table 1. Approximately $45.1 \%$ of the participants reported consuming yoghurt less than once per week, while only $1.5 \%$ consumed yoghurt twice a day or more. Compared with those in the lower category of yoghurt consumption, the higher category of yoghurt consumption included a larger proportion of women and participants in this category were also younger, had a lower BMI and higher physical activity, were less likely to be married, more likely to live alone, had a higher education level and were more likely to be employed as Managers. Yoghurt consumption was inversely related to smoking and alcohol use, and positively associated with milk consumption. Mean total energy intake was significantly higher across the yoghurt consumption quartiles.

The crude and adjusted association between categories of yoghurt consumption and depressive symptoms are shown in Table 2. There were no differences on either depression criterion among participants who rarely ate yoghurt and who consumed it 1-3 times or 4-7 times per week. But depressive symptoms were more common in the group who consumed yoghurt twice or more per day. In all models, there was therefore a positive association between ORs of the depressive symptom and categories of yoghurt consumption. Taking the cutoff of 45 for example, the crude ORs $(95 \% \mathrm{CI})$ for depressive symptoms across yoghurt categories were $0.97(0.90,1.06), 0.96(0.86,1.07)$ and $2.06(1.59,2.65)$. These results were similar after adjustment for multiple confounding factors, so in the fully adjusted models, the ORs for depressive symptoms across yoghurt categories were $1.05(0.96,1.15), 1.02(0.91$, 
$1721.15)$ and $2.10(1.61,2.73)$. Participants who consumed yoghurt more than twice per day had 173 the highest prevalence of depressive symptoms. Similar effects were observed when SDS $\geq$ 17450 was used as the definition of depressive symptoms. No significant interaction between 175 yoghurt consumption and sex was found $(\operatorname{SDS} \geq 50, p$ for interaction=0.29). Since depressive 176 status is also related to unhealthy eating habits and appetite [31,32], a sensitivity analysis was 177 added by excluding those who had very low (under 2.5\%) or high (upper $2.5 \%$ ) energy intake. 178 However, the exclusion of these individuals did not change the pattern of results. 


\section{Discussion}

The aim of this study was to examine the relationship between yoghurt consumption and depressive symptoms among adults in China. We expected on the basis of animal and experimental human studies that more yoghurt consumption would be associated with lower depressive symptoms, but this was not found. Habitual yoghurt consumption 1-3 times per week or 4-7 times per week was not related to depressive symptoms, while the small group who consumed yoghurt twice or more per day had the highest risk of depressive symptoms. These findings were consistent after adjustment for multiple confounding factors.

To our knowledge, this is the first large population study of the association between yoghurt consumption and depressive symptoms in adults. Previous animal studies have provided abundant evidence to suggest that probiotics can modulate the stress response and improve depression and anxiety symptoms $[13,14,16]$. This preclinical evidence has suggested that modification of microbial ecology, for example by supplements or foods containing probiotics, may be used therapeutically to modify stress responses and symptoms of anxiety and depression in humans [33-35]. As a commonly consumed food with a high content of probiotics, yoghurt is a preferred candidate for this role $[15,20,36]$. However, human studies directly examining the association between yoghurt consumption and mood remain scarce. One study found that subjects who initially scored in the lowest third for depressed mood showed significant improvement in symptoms after 3-week consumption of a probiotic-containing yoghurt, while the yoghurt and placebo group were unable to make a difference in those with the highest baseline mood scores [19]. Another randomized clinical trial found that daily administration of a combination of bacteria reduced psychological distress to a greater extent in healthy volunteers than did placebo [17]. However, it was a 
probiotic formulation (Lactobacillus helveticus R0052 and Bifidobacterium longum R0175) rather than yoghurt that has been used in this study.

Our study found no significant difference in the ORs for the participants who consumed yoghurt no more than once per day compared with those whose consumption frequency was less than once per week. This is consistent with a previous population study in Spain, which did not find any beneficial effects of habitual yoghurt consumption on mental health [22]. Interestingly, when the frequency of consumption was more than twice a day, the risk of depressive symptoms was dramatically increased. Even after multiple adjustments, the ORs for depressive symptoms for this group was still $110 \%$ higher than in the lowest consumption group.

Since there is still no persuasive evidence for any negative impact of probiotics on mental health, a possible explanation is that there might be something other than the probiotics contained in yoghurt that accounted for this adverse result. The first concern might be the added sugar or sweetener. On its own, yoghurt is a low calorie, high nutrient and protein-rich food. However, many manufactured yoghurts contain a substantial amount of sugar or artificial sweeteners. Sweetened yoghurt used to be listed as one of the foods that contained the most added sugars in the American diet [37], and a 150g (5oz) serving of some 'zero fat' yoghurts can contain as much as $20 \mathrm{~g}(0.7 \mathrm{oz})$ of sugar. Epidemiologic studies have suggested a positive association between consumption of sweets and depressive symptoms $[38,39]$. Our previous study based on the same population also found that higher consumption of soft drinks, which contain a large amount of sugar, was related to a higher prevalence of depressive symptoms [40]. In the present study, we were unable to evaluate sugary and nonsugary yoghurt separately. But as we known, most commercial yoghurts in China are 
sugar-sweetened, which would increase the possibility of excessive sugar intake through the long-term frequent consumption of yoghurt.

The strength of the study was the large sample size and the adjustment for a number of potential confounders. However, since only a relatively small subset of participants who consumed large amounts of yoghurt displayed a higher level of depressive symptoms, it should be cautious to draw any conclusion about the mental detrimental effects of yoghurt consumption. The cross-sectional nature of the study did not allow us to determine the direction of causality. An alternative explanation of current findings might be that high level of depression causes increased consumption of yoghurt. From the descriptive statistics of the cohort (Table 1), it appears that high yoghurt consumption was associated with many healthier characteristics such as lower BMI, higher levels of physical activity, and less smoking and drinking. Yoghurt was traditionally thought to be a nutrient-dense milk product with health-promoting effects and is often categorized as one of the healthiest food choices alongside with fruits and vegetables[41]. We cannot exclude the possibility that the participants who were already depressed would try to eat more "healthy" foods including yoghurt as a form of self-medication.

This study has a number of limitations and the results should be interpreted with caution. First, depressive symptoms were assessed with a self-report questionnaire rather than diagnostic psychiatric interviews. Total scores on the SDS do not correspond with a clinical diagnosis of depression but rather indicate the level of depressive symptoms that may be of clinical relevance. Therefore, a larger population study that uses a standardized comprehensive structured diagnostic interview should be undertaken to confirm the associations with depression. Second, this is a cross-sectional study, which precludes 
causality inferences about the association. Although we have statistically adjusted for many 250 potential confounding factors, we may not have fully captured relevant aspects of those 251 factors. Third, if there is a mental health effect associated with probiotics contained in 252 yoghurt, it would presumably depend on their numbers in the product. However, there exist 253 some dairy products on Chinese market labeled as yoghurts that are just pasteurised milk 254 with no active cultures. Furthermore, the ability of the probiotic organisms contained in 255 yoghurt to survive and multiply in the gastrointestinal tract is also difficult to verify in an 256 epidemiological study of this type. Therefore, further clinical trials in which probiotics 257 contents are strictly administered are still required to determine the exact relationship 258 between yoghurt consumption and depressive symptoms. In summary, habitual yoghurt consumption did not show an association with 260 improved mental status in this large-scale study. On the contrary, the small subset of 261 participants who had a relatively high frequency of yoghurt consumption ( $\geq$ twice/day) 262 displayed a higher risk of depressive symptoms. Thus, caution should be used when 263 recommending yoghurt as an adjuvant therapy for symptoms of depression in humans. 264 Further prospective studies with long-term follow-up will be necessary to confirm the 265 preliminary findings of this study. 


\section{Acknowledgments}

This study was supported by grants from the National Natural Science Foundation of China (Nos. 81673166, 81372118, 81372467 and 81302422), the Key Technologies R\&D Program of Tianjin (Nos. 11ZCGYSY05700, 12ZCZDSY20400, 13ZCZDSY20200, and 15YFYZSY00020), the National Science and Technology Support Program (No. 2012BAI02B02), Chinese Nutrition Society (CNS) Nutrition Research Foundation-DSM Research Fund (Nos. 2014-071, 2016-046 and 2016-023), the Technologies Development Program of Beichen District of Tianjin (Nos. bcws2013-21, bcws2014-05 and 2015-SHGY02), the Technologies Project of Tianjin Binhai New Area (Nos. 2013-02-04 and 2013-0206), the Science Foundation of Tianjin Medical University (Nos. 2010KY28 and 2013KYQ24), the Key Laboratory of Public Health Safety (Fudan University), Ministry of Education (No. GW2014-5), the National Training Programs of Innovation and Entrepreneurship for Undergraduates (No. 201510062013), Ministry of Education Project of Humanities and Social Sciences (No. 12YJC190036), Scholarship from China Scholarship Council (CSC). 


\section{References}

1. Chesney E, Goodwin GM, Fazel S (2014) Risks of all-cause and suicide mortality in mental disorders: a meta-review. World psychiatry : official journal of the World Psychiatric Association 13 (2):153-160. doi:10.1002/wps.20128

2. Sanhueza C, Ryan L, Foxcroft DR (2013) Diet and the risk of unipolar depression in adults: systematic review of cohort studies. Journal of human nutrition and dietetics : the official journal of the British Dietetic Association 26 (1):56-70. doi:10.1111/j.1365277X.2012.01283.X

3. Lopresti AL, Hood SD, Drummond PD (2013) A review of lifestyle factors that contribute to important pathways associated with major depression: diet, sleep and exercise. Journal of affective disorders 148 (1):12-27. doi:10.1016/j.jad.2013.01.014

4. Skarupski KA, Tangney C, Li H, Ouyang B, Evans DA, Morris MC (2010) Longitudinal association of vitamin B-6, folate, and vitamin B-12 with depressive symptoms among older adults over time. The American journal of clinical nutrition 92 (2):330-335. doi:10.3945/ajen.2010.29413

5. Vashum KP, McEvoy M, Milton AH, McElduff P, Hure A, Byles J, Attia J (2014) Dietary zinc is associated with a lower incidence of depression: findings from two Australian cohorts. Journal of affective disorders 166:249-257. doi:10.1016/j.jad.2014.05.016

6. Colangelo LA, He K, Whooley MA, Daviglus ML, Liu K (2009) Higher dietary intake of long-chain omega-3 polyunsaturated fatty acids is inversely associated with depressive symptoms in women. Nutrition 25 (10):1011-1019. doi:10.1016/j.nut.2008.12.008

7. Niu K, Guo H, Kakizaki M, Cui Y, Ohmori-Matsuda K, Guan L, Hozawa A, 
Kuriyama S, Tsuboya T, Ohrui T, Furukawa K, Arai H, Tsuji I, Nagatomi R (2013) A tomatorich diet is related to depressive symptoms among an elderly population aged 70 years and over: a population-based, cross-sectional analysis. Journal of affective disorders 144 (12):165-170. doi:10.1016/j.jad.2012.04.040

8. Su Q, Yu B, He H, Zhang Q, Meng G, Wu H, Du H, Liu L, Shi H, Xia Y, Guo X, Liu X, Li C, Bao X, Gu Y, Fang L, Yu F, Yang H, Sun S, Wang X, Zhou M, Jia Q, Zhao H, Song K, Niu K (2016) Nut Consumption Is Associated with Depressive Symptoms among Chinese Adults. Depression and anxiety. doi:10.1002/da.22516

9. Friedrich MJ (2015) Unraveling the influence of gut microbes on the mind. Jama 313 (17):1699-1701. doi:10.1001/jama.2015.2159

10. WHO/FAO (2011) Codex Alimentarius. Milk and milk products. WHO/FAO. http://www.fao.org/docrep/015/i2085e/i2085e00.pdf.

11. Alvaro E, Andrieux C, Rochet V, Rigottier-Gois L, Lepercq P, Sutren M, Galan P, Duval Y, Juste C, Dore J (2007) Composition and metabolism of the intestinal microbiota in consumers and non-consumers of yogurt. The British journal of nutrition 97 (1):126-133. doi:10.1017/S0007114507243065

12. Garcia-Albiach R, Pozuelo de Felipe MJ, Angulo S, Morosini MI, Bravo D, Baquero F, del Campo R (2008) Molecular analysis of yogurt containing Lactobacillus delbrueckii subsp. bulgaricus and Streptococcus thermophilus in human intestinal microbiota. The American journal of clinical nutrition 87 (1):91-96

13. Bravo JA, Forsythe P, Chew MV, Escaravage E, Savignac HM, Dinan TG, Bienenstock J, Cryan JF (2011) Ingestion of Lactobacillus strain regulates emotional behavior and central GABA receptor expression in a mouse via the vagus nerve. Proceedings 
of the National Academy of Sciences of the United States of America 108 (38):16050-16055. doi:10.1073/pnas.1102999108

14. Desbonnet L, Garrett L, Clarke G, Kiely B, Cryan JF, Dinan TG (2010) Effects of the probiotic Bifidobacterium infantis in the maternal separation model of depression. Neuroscience 170 (4):1179-1188. doi:10.1016/j.neuroscience.2010.08.005

15. Foster JA, McVey Neufeld KA (2013) Gut-brain axis: how the microbiome influences anxiety and depression. Trends in neurosciences 36 (5):305-312. doi:10.1016/j.tins.2013.01.005

16. Dinan TG, Stanton C, Cryan JF (2013) Psychobiotics: a novel class of psychotropic. Biological psychiatry 74 (10):720-726. doi:10.1016/j.biopsych.2013.05.001

17. Messaoudi M, Lalonde R, Violle N, Javelot H, Desor D, Nejdi A, Bisson JF, Rougeot C, Pichelin M, Cazaubiel M, Cazaubiel JM (2011) Assessment of psychotropic-like properties of a probiotic formulation (Lactobacillus helveticus R0052 and Bifidobacterium longum R0175) in rats and human subjects. The British journal of nutrition 105 (5):755-764. doi:10.1017/S0007114510004319

18. Rao AV, Bested AC, Beaulne TM, Katzman MA, Iorio C, Berardi JM, Logan AC (2009) A randomized, double-blind, placebo-controlled pilot study of a probiotic in emotional symptoms of chronic fatigue syndrome. Gut pathogens 1 (1):6. doi:10.1186/1757$4749-1-6$

19. Benton D, Williams C, Brown A (2007) Impact of consuming a milk drink containing a probiotic on mood and cognition. European journal of clinical nutrition 61 (3):355-361. doi:10.1038/sj.ejcn.1602546

20. Tillisch K, Labus J, Kilpatrick L, Jiang Z, Stains J, Ebrat B, Guyonnet D, Legrain- 
Raspaud S, Trotin B, Naliboff B, Mayer EA (2013) Consumption of fermented milk product with probiotic modulates brain activity. Gastroenterology 144 (7):1394-1401, 1401 e13911394. doi:10.1053/j.gastro.2013.02.043

21. Sanchez M, Darimont C, Panahi S, Drapeau V, Marette A, Taylor VH, Dore J, Tremblay A (2017) Effects of a Diet-Based Weight-Reducing Program with Probiotic Supplementation on Satiety Efficiency, Eating Behaviour Traits, and Psychosocial Behaviours in Obese Individuals. Nutrients 9 (3). doi:10.3390/nu9030284

22. Lopez-Garcia E, Leon-Munoz L, Guallar-Castillon P, Rodriguez-Artalejo F (2015) Habitual yogurt consumption and health-related quality of life: a prospective cohort study. Journal of the Academy of Nutrition and Dietetics 115 (1):31-39. doi:10.1016/j.jand.2014.05.013

23. Gu Y, Li H, Bao X, Zhang Q, Liu L, Meng G, Wu H, Du H, Shi H, Xia Y, Su Q, Fang L, Yu F, Yang H, Yu B, Sun S, Wang X, Zhou M, Jia Q, Guo Q, Chang H, Wang G, Huang G, Song K, Niu K (2017) The Relationship Between Thyroid Function and the Prevalence of Type 2 Diabetes Mellitus in Euthyroid Subjects. The Journal of clinical endocrinology and metabolism 102 (2):434-442. doi:10.1210/jc.2016-2965

24. Lee HC, Chiu HF, Wing YK, Leung CM, Kwong PK, Chung DW (1994) The Zung Self-rating Depression Scale: screening for depression among the Hong Kong Chinese elderly. Journal of geriatric psychiatry and neurology 7 (4):216-220

25. Xu L, Ren J, Cheng M, Tang K, Dong M, Hou X, Sun L, Chen L (2004) Depressive symptoms and risk factors in Chinese persons with type 2 diabetes. Archives of medical research 35 (4):301-307. doi:10.1016/j.arcmed.2004.04.006

26. Zung WW (1965) A Self-Rating Depression Scale. Archives of general psychiatry 
$12: 63-70$

27. Yang Y, Wang G, Pan X (2002) China food composition. Peking University Medical Press, Beijing 329

28. Alberti KG, Eckel RH, Grundy SM, Zimmet PZ, Cleeman JI, Donato KA, Fruchart JC, James WP, Loria CM, Smith SC, Jr., International Diabetes Federation Task Force on E, Prevention, Hational Heart L, Blood I, American Heart A, World Heart F, International Atherosclerosis S, International Association for the Study of O (2009) Harmonizing the metabolic syndrome: a joint interim statement of the International Diabetes Federation Task Force on Epidemiology and Prevention; National Heart, Lung, and Blood Institute; American Heart Association; World Heart Federation; International Atherosclerosis Society; and International Association for the Study of Obesity. Circulation 120 (16):1640-1645. doi:10.1161/CIRCULATIONAHA.109.192644

29. China SSBo (2015) Chinese Standard Classification of Occupations. China Labor and Social Security Press, Beijing

30. Craig CL, Marshall AL, Sjostrom M, Bauman AE, Booth ML, Ainsworth BE, Pratt M, Ekelund U, Yngve A, Sallis JF, Oja P (2003) International physical activity questionnaire: 12-country reliability and validity. Medicine and science in sports and exercise 35 (8):13811395. doi:10.1249/01.MSS.0000078924.61453.FB

31. Andreasson A, Arborelius L, Erlanson-Albertsson C, Lekander M (2007) A putative role for cytokines in the impaired appetite in depression. Brain, behavior, and immunity 21 (2):147-152. doi:10.1016/j.bbi.2006.08.002

32. Cassano P, Fava M (2002) Depression and public health: an overview. Journal of psychosomatic research $53(4): 849-857$ 
33. Logan AC, Katzman M (2005) Major depressive disorder: probiotics may be an adjuvant therapy. Medical hypotheses 64 (3):533-538. doi:10.1016/j.mehy.2004.08.019

34. Cryan JF, Dinan TG (2012) Mind-altering microorganisms: the impact of the gut microbiota on brain and behaviour. Nature reviews Neuroscience 13 (10):701-712. doi: $10.1038 / \mathrm{nrn} 3346$

35. Bruce-Keller AJ, Salbaum JM, Luo M, Blanchard Et, Taylor CM, Welsh DA, Berthoud HR (2015) Obese-type gut microbiota induce neurobehavioral changes in the $\begin{array}{llllll}\text { absence of } & \text { obesity. } & \text { Biological } & \text { psychiatry } 67-615 \text {. }\end{array}$ doi:10.1016/j.biopsych.2014.07.012

36. Bested AC, Logan AC, Selhub EM (2013) Intestinal microbiota, probiotics and mental health: from Metchnikoff to modern advances: Part I - autointoxication revisited. Gut pathogens 5 (1):5. doi:10.1186/1757-4749-5-5

37. Guthrie JF, Morton JF (2000) Food sources of added sweeteners in the diets of Americans. Journal of the American Dietetic Association 100 (1):43-51, quiz 49-50. doi:10.1016/S0002-8223(00)00018-3

38. Jeffery RW, Linde JA, Simon GE, Ludman EJ, Rohde P, Ichikawa LE, Finch EA (2009) Reported food choices in older women in relation to body mass index and depressive symptoms. Appetite 52 (1):238-240. doi:10.1016/j.appet.2008.08.008

39. Mikolajczyk RT, El Ansari W, Maxwell AE (2009) Food consumption frequency and perceived stress and depressive symptoms among students in three European countries. Nutrition journal 8:31. doi:10.1186/1475-2891-8-31

40. Yu B, He H, Zhang Q, Wu H, Du H, Liu L, Wang C, Shi H, Xia Y, Guo X, Liu X, Li C, Bao X, Su Q, Meng G, Chu J, Mei Y, Sun S, Wang X, Zhou M, Jia Q, Zhao H, Song K, 
Niu K (2015) Soft drink consumption is associated with depressive symptoms among adults in China. Journal of affective disorders 172:422-427. doi:10.1016/j.jad.2014.10.026

41. Darmon N, Vieux F, Maillot M, Volatier JL, Martin A (2009) Nutrient profiles discriminate between foods according to their contribution to nutritionally adequate diets: a validation study using linear programming and the SAIN,LIM system. The American journal of clinical nutrition 89 (4):1227-1236. doi:10.3945/ajen.2008.26465 


\section{TABLE 1}

Participants characteristics by frequency of yoghurt consumption.

Frequency of yoghurt consumption

\begin{tabular}{|c|c|c|c|c|c|}
\hline & \multicolumn{4}{|c|}{ Frequency of yoghurt consumption } & \multirow[b]{2}{*}{$P$ values a } \\
\hline & $\begin{array}{c}<\text { once/week or hardly } \\
\text { ever } \\
(\mathrm{n}=8,840)\end{array}$ & $\begin{array}{l}1-3 \text { times/week } \\
(n=7,134)\end{array}$ & $\begin{array}{l}\text { 4-7 times/week } \\
(\mathrm{n}=3,324)\end{array}$ & $\begin{array}{l}\geqslant \text { twice/day } \\
(\mathrm{n}=298)\end{array}$ & \\
\hline Age (y) & $43.7(43.4,43.9)^{b}$ & $38.7(38.4,38.9)$ & $39.8(39.4,40.2)$ & $41.2(39.9,42.5)$ & $<0.0001$ \\
\hline Sex (males, \%) & 63.7 & 49.5 & 40.4 & 44.3 & $<0.0001$ \\
\hline BMI $\left(\mathrm{kg} / \mathrm{m}^{2}\right)^{\mathrm{c}}$ & $25(25,25.1)$ & $24.3(24.2,24.3)$ & $24.1(24,24.2)$ & $24.3(23.8,24.7)$ & $<0.0001$ \\
\hline Metabolic syndromes (yes, \%) & 31.3 & 22.2 & 20.5 & 23.2 & $<0.0001$ \\
\hline Physical activity (MET $\times$ hour/week) & $9.4(9.1,9.6)$ & $9.8(9.5,10.1)$ & $11(10.5,11.5)$ & $9.9(8.5,11.6)$ & $<0.0001$ \\
\hline Total energy intake (kcal/d) & $1893.4(1882.4,1904.5)$ & $\begin{array}{c}\text { 2039.1(2025.8 } \\
2052.4)\end{array}$ & $\begin{array}{c}\text { 2157.1(2136.6 } \\
2177.8)\end{array}$ & $2474.0(2396.4,2554.2)$ & $<0.0001$ \\
\hline SDS score ${ }^{c}$ & $36.1(35.9,36.2)$ & $36(35.8,36.1)$ & $35.7(35.5,36)$ & $38.8(37.9,39.8)$ & $<0.0001$ \\
\hline \multicolumn{6}{|l|}{ Smoking status (\%) } \\
\hline Smoker & 28.6 & 17.6 & 12.8 & 15.4 & $<0.0001$ \\
\hline Ex-smoker & 7.3 & 4.5 & 4.2 & 5.9 & $<0.0001$ \\
\hline Non-smoker & 64.1 & 77.9 & 83.1 & 78.7 & $<0.0001$ \\
\hline
\end{tabular}




\begin{tabular}{|c|c|c|c|c|c|}
\hline \multicolumn{6}{|l|}{ Drinker (\%) } \\
\hline Everyday & 7.8 & 2.9 & 2.7 & 4.1 & $<0.0001$ \\
\hline Sometime & 58.6 & 59.1 & 54.8 & 52.0 & $<0.001$ \\
\hline Ex-drinker & 9.1 & 8.7 & 9.2 & 8.1 & 0.76 \\
\hline Non-drinker & 24.5 & 29.4 & 33.3 & 35.8 & $<0.0001$ \\
\hline Marital status (married, \%) & 90.2 & 84.3 & 81.0 & 78.2 & $<0.0001$ \\
\hline Cohabitants (yes, \%) & 8.1 & 9.0 & 10.5 & 12.2 & $<0.0001$ \\
\hline Education ( $\geqslant$ College graduate, $\%)$ & 57.6 & 74.2 & 70.9 & 66.6 & $<0.0001$ \\
\hline \multicolumn{6}{|l|}{ Occupation (\%) } \\
\hline Managers & 39.5 & 45.2 & 49.1 & 48.0 & $<0.0001$ \\
\hline Professionals & 18.0 & 18.2 & 13.6 & 13.6 & $<0.0001$ \\
\hline Other & 42.5 & 36.6 & 37.3 & 38.4 & $<0.0001$ \\
\hline Household income ( $\geqslant 10,000$ Yuan, $\%)$ & 33.2 & 35.9 & 30.5 & 24.7 & 0.02 \\
\hline Social contact (yes, \%) & 60.2 & 61.9 & 65.4 & 61.8 & $<0.0001$ \\
\hline \multicolumn{6}{|l|}{ Milk consumption (\%) } \\
\hline$<$ once/week or hardly ever & 66.3 & 37.8 & 35.1 & 34.9 & $<0.0001$ \\
\hline 1-3 times/ week & 19.9 & 43.5 & 26.4 & 15.4 & $<0.0001$ \\
\hline 4-7 times/ week & 13.8 & 18.6 & 38.4 & 49.7 & $<0.0001$ \\
\hline
\end{tabular}


${ }^{a}$ Analysis of variance or logistic regression analysis.

${ }^{b}$ Least square geometric mean (95\% confidence interval) (all such values).

${ }^{\mathrm{c}} \mathrm{BMI}$, body mass index; SDS, self-rating depression scale. 


\section{TABLE 2}

Adjusted relationships of the frequency of yoghurt consumption to depressive symptom.

\begin{tabular}{|c|c|c|c|c|c|}
\hline & & Frequency of yog & consumption & & \\
\hline & $\begin{array}{l}<\text { once/week or hardly } \\
\text { ever } \\
\qquad(\mathrm{n}=8,840)\end{array}$ & $\begin{array}{c}1-3 \text { times/week } \\
(n=7,134)\end{array}$ & $\begin{array}{l}\text { 4-7 times/week } \\
(\mathrm{n}=3,324)\end{array}$ & $\begin{array}{l}\geq \text { twice/day } \\
\quad(n=298)\end{array}$ & $P$ for trend ${ }^{a}$ \\
\hline $\begin{array}{l}\text { No. of depressive symptom (SDS } \\
\geq 45)^{\text {b }}\end{array}$ & 1513 & 1193 & 549 & 89 & \\
\hline Crude & 1.00 & $0.97(0.90,1.06)^{\mathrm{c}}$ & $0.96(0.86,1.07)$ & $2.06(1.59,2.65)$ & $<0.0001$ \\
\hline Age, sex, and BMI-adjusted ${ }^{\mathrm{b}}$ & 1.00 & $0.95(0.87,1.03)$ & $0.92(0.82,1.03)$ & $2.00(1.54,2.57)$ & $<0.0001$ \\
\hline Mutiple-adjusted ${ }^{\mathrm{d}}$ & 1.00 & $1.05(0.96,1.15)$ & $1.02(0.91,1.15)$ & $2.10(1.61,2.73)$ & $<0.0001$ \\
\hline $\begin{array}{l}\text { No. of depressive symptom (SDS } \\
\geq 50 \text { ) }\end{array}$ & 566 & 460 & 230 & 34 & \\
\hline Crude & 1.00 & $1.01(0.89,1.14)$ & $1.09(0.93,1.27)$ & $1.88(1.28,2.68)$ & 0.014 \\
\hline Age, sex, and BMI-adjusted & 1.00 & $1.00(0.87,1.14)$ & $1.07(0.91,1.25)$ & $1.85(1.26,2.64)$ & 0.031 \\
\hline Mutiple-adjusted ${ }^{\mathrm{d}}$ & 1.00 & $1.14(0.99,1.31)$ & $1.20(1.01,1.43)$ & $1.90(1.28,2.75)$ & $<0.0001$ \\
\hline
\end{tabular}


${ }^{\mathrm{b}}$ SDS, self-rating depression scale; BMI, body mass index.

${ }^{c}$ Adjusted odds ratio (95\% confidence interval) (all such values).

d Adjusted for age, sex, BMI, smoking status, drinking status, physical activity, marital status, total energy intake, household incomes, occupations, educational levels, social contact, cohabitants, metabolic syndrome and milk consumption. 